\title{
Sequential feeding with diets varying in amino acid content for growing-finishing pigs
}

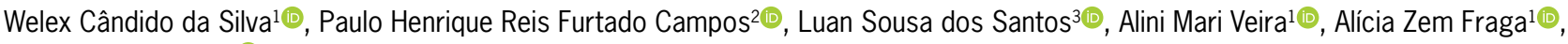 \\ Luciano Hauschild ${ }^{*}$ (1)
}

1 Universidade Estadual Paulista/FCAV- Depto. de Zootecnia, Via de Acesso Prof. Paulo Donato Castellane, s/n - 14884900 - Jaboticabal, SP - Brasil.

UUniversidade Federal de Viçosa/CCA - Depto. de Zootecnia, Av. Peter Henry Rolfs, s/n - 36570-900 - Viçosa, MG -

Brasil.

3Universidade Federal Rural do Rio de Janeiro/Instituto de Zootecnia - Depto. de Nutrição Animal e Pastagem, BR 465, km 7 - 23897-000 - Seropédica, RJ - Brasil.

*Corresponding author <luciano.hauschild@unesp.br>

Edited by: Gerson Barreto Mourão

Received September 13, 2019

Accepted February 12, 2020
ABSTRACT: This study aimed to evaluate the effects of daily phase feeding (DP) and sequential feeding (SEQ) on the feeding behavior, performance, and body composition of growing-finishing pigs. Sixty barrows at $29.7 \pm 2.8 \mathrm{~kg}$ body weight (BW) were assigned to one of four treatments: DP with a blended proportion of feeds A (high nutrient density) and B (low nutrient density) was adjusted to match $100 \%$ of daily amino acid (AA) diet recommendations (DP100); a negative treatment, which matched $70 \%$ of daily AA diet recommendations (DP70); and two SEQ with a blend of feeds $A$ and $B$, adjusted twice a day (at $00 \mathrm{~h} 00$ and $12 \mathrm{~h} 00$ ), to match 70 or $110 \%$ of daily AA diet recommendations during two $12 \mathrm{~h}$ intervals: SEQ110-70 and SEQ70-110. DP70 and SEQ showed a lower feed consumption rate compared to DP100 $(p<0.05)$. Compare to DP100, pigs in both SEQ programs had a similar average daily feed intake (ADFI), average daily gain (ADG), feed efficiency ratio (G:F) and body fat and lean mass ( $p>0.05$ ). SEQ110-70 and SEQ70-110 showed similar ADFI, ADG, G:F and body lean mass ( $p>0.05$ ). However, fat gain was greater in SEQ110-70 than in SEQ70-110 $(p<0.05)$. Overall, the SEQ program does not improve performance and body composition. Furthermore, feeding pigs a diet with a higher $\mathrm{AA}$ level during the first $12 \mathrm{~h}$ of the day and a lower $\mathrm{AA}$ level during the remainder of the day increases fat deposition.

Keywords: circadian rhythms, daily feeding phase, feeding techniques, precision feeding

\section{Introduction}

A promising strategy for reducing nutrient supply and excretion consists of the use of daily feeding techniques in which pigs are fed an adjusted diet according to their daily nutrient requirements (Pomar et al., 2014). However, this technique has not yet been considered in association with variations in voluntary feed intake and nutrient metabolism that occurs during the 24-hour-day cycle.

Studies have shown that protein and carbohydrate metabolisms fluctuate during the day because of the circadian rhythms of cortisol, insulin, and feed intake (Koopmans et al., 2005; Koopmans et al., 2006). In addition, a diurnal pattern is observed for the metabolism of insulin-stimulated amino acids (AA) and is characterized by a greater efficiency of AA utilization (19 \%) in the morning compared to the evening (Koopmans et al., 2006).

Therefore, we hypothesized that feeding animals with different diets varying in AA content in the morning and in the evening (low-high and high-low AA concentration diets) according to their metabolic status might improve their ability to use nutrients with positive effects on growth performance. The practice of alternating diets is called sequential feeding (Bouvarel et al., 2004). Besides meeting the nutrient requirements throughout the growth period (long term), the use of sequential feeding also allows considering the cyclic nutrient requirements during the day (short term).

Therefore, this study evaluated whether the use of the sequential feeding techniques with dietary AA content varying during the morning and evening periods (low-high and high-low AA concentration diets) affect the feeding behavior, growth performance, and body composition of pigs. In order to provide diets to pigs with different AA content during the morning and evening, a 12-h cycle interval period during the day (beginning at 00h00) was used.

\section{Materials and Methods}

All the experimental procedures were reviewed and approved by the University Ethical Committee for Care and Use of Experimental Animals (Protocol Number 2296115).

\section{Animals, housing and management}

Sixty barrows with $15 \mathrm{~kg}$ body weight (BW) of the same high-performance genotype (Camborough $\times$ AGPIC337; Agroceres PIC, Patos de Minas, Brazil) were shipped in a single batch to the swine research facilities in southeastern Brazil, Jaboticabal, São Paulo $\left(21^{\circ} 15^{\prime} \mathrm{S}\right.$, $48^{\circ} 19^{\prime} \mathrm{W}$, altitude of $605 \mathrm{~m}$ ). One transponder (plastic button tag containing passive transponders of radio frequency identification; Allflex, Joinville, SC, Brazil) was tagged to the right ear of each pig using specific tagger pliers, and animals were introduced to the electronic feeders. All pigs were housed under natural lighting conditions (Mar, Apr, and May) in a single pen $\left(95 \mathrm{~m}^{2}\right)$ with full concrete flooring equipped with five automatic feeders (AIPF, Automatic and Intelligent Precision Feeder, University of Lleida, Lleida, Spain). The experimental facility had an evaporative pad cooling system that was controlled automatically to keep pigs under thermoneutral conditions. Pigs remained 
in the experimental facility for 106 days including 32 days of adaptation and 84 days of experimental period. During adaptation, pigs received a commercial corn and soybean meal-based diet formulated to meet their nutritional requirements (NRC, 2012).

Upon reaching $29.7 \pm 2.8 \mathrm{~kg}$ of $\mathrm{BW}$, the experimental period was started and pigs were randomly assigned to one of four treatments (15 pigs per treatment). The experimental period (84 days) was divided into three experimental phases: phase 1 (from 0 to 35 days), phase 2 (from 36 to 63 days), and phase 3 (from 64 to 84 days). During the adaptation and experimental periods, pigs had free access to water, and feed was provided ad libitum through AIPF. The functioning of these feeders was previously described (Andretta et al., 2014). Briefly, the feeding stations identify each pig every time the animal sticks its head into the feeder and delivers, in response to each animal request, a blend of feeds $\mathrm{A}$ and $\mathrm{B}$ containing the estimated concentration of lysine (Lys) required by the animal for the day, corrected according to the assigned experimental treatment (see Diets and nutrient requirement assessment section). Therefore, any pig in the pen had access to any of the feeders and received the diet prescribed for that animal. Access to the feeder was limited to one pig per time.

Feeder calibration (matching between the amounts of feed registered and provided) was checked weekly. One serving consisted of $25 \mathrm{~g}$ of feed that was delivered upon request. A time lag (18 s) was imposed to ensure that pigs consumed each serving before requesting a new one. The feeders were equipped with a monitoring tool that continuously registered each visit of each pig with start and stop time (day, hour, minute, and second) and the amount of feed consumed.

\section{Diets and nutrient requirement assessment}

Two experimental feeds were used during the experiment (feeds A and B; Table 1). The feeds were formulated according to the method proposed by Letourneau Montminy et al. (2005). In this method, two feeds are formulated simultaneously, minimizing feed costs and ensuring that the blend satisfies the requirements of the animals throughout the growing period. Feeds A and B differed in standardized ileal digestible (SID) Lys content and the concentration of other nutrients. Feed A was formulated with high nutrient density to satisfy the estimated requirements of a pig population at the beginning of the growing period (first day) and feed B was formulated with a low nutrient density to satisfy the estimated requirements of a pig population at the end of the finishing period (last day). The daily nutrient requirements for the growth-finishing period were calculated a priori by simulation according to the method proposed by NRC (2012). Soybean meal was used as the main source protein, and corn and fat were the main energy sources. Synthetic AA (L-lysine $\mathrm{HCl}$, DL-methionine, L-threonine, L-tryptophan and L-valine) was used to improve amino-acid balance of
Table 1 - Ingredient formulas and chemical composition of experimental feeds.

\begin{tabular}{|c|c|c|}
\hline \multirow[b]{2}{*}{ Item } & \multicolumn{2}{|c|}{ Feeds } \\
\hline & $\begin{array}{c}\text { A: high } \\
\text { nutrient density }\end{array}$ & $\begin{array}{c}\text { B: lower } \\
\text { nutrient density }\end{array}$ \\
\hline \multicolumn{3}{|l|}{ Ingredients (as-feed base, \%) } \\
\hline Corn & 70.12 & 87.10 \\
\hline Soybean meal & 25.70 & 9.30 \\
\hline Dicalcium phosphate & 1.61 & 0.70 \\
\hline Calcium carbonate & 0.85 & 0.48 \\
\hline Dextrin & 0.50 & 0.50 \\
\hline Vitamin and mineral premix ${ }^{1}$ & 0.04 & 0.04 \\
\hline Salt & 0.17 & 0.17 \\
\hline L-Lysine $\mathrm{HCl} 78$ \% & 0.51 & - \\
\hline DL-Methionine 99 \% & 0.20 & - \\
\hline L-Threonine $99 \%$ & 0.15 & - \\
\hline L-Tryptophan 98 \% & 0.03 & - \\
\hline L-Valine $100 \%$ & 0.06 & - \\
\hline Choline chloride 60 (52 \%) & 0.06 & 0.07 \\
\hline Kaolin & - & 1.64 \\
\hline \multicolumn{3}{|l|}{ Chemical composition } \\
\hline Dry matter (\%) & 87.13 & 87.61 \\
\hline Crude Protein (\%) & 18.04 & 10.71 \\
\hline Total lysine (\%) & 1.34 & 0.46 \\
\hline SID lysine $(\%)^{2}$ & 1.21 & 0.42 \\
\hline Net Energy $\left(\mathrm{Mcal} \mathrm{kg}^{-1}\right)^{2}$ & 2.51 & 2.59 \\
\hline Calcium (\%) & 0.82 & 0.43 \\
\hline Phosphorus (\%) & 0.61 & 0.37 \\
\hline Digestible phosphorus (calculated², \%) & 0.42 & 0.24 \\
\hline Ash (\%) & 3.71 & 3.52 \\
\hline
\end{tabular}

SID = standardized ileal digestible; ${ }^{1}$ Supplied the following per $\mathrm{kg}$ of diet: vitamin A, $5.250 \mathrm{IU}$; vitamin D3, $750 \mathrm{IU}$; vitamin E, $11 \mathrm{IU}$; vitamin $\mathrm{K} 3,1.5$ mg; vitamin B1, 1 mg; vitamin B2, 2.4 mg; vitamin B6, 1 mg; niacin, 30 mg; pantothenic acid, $8.1 \mathrm{mg}$; folic acid, $0.53 \mathrm{mg}$; biotin, $0.05 \mathrm{mg}$; vitamin B12, $16.5 \mathrm{mg}$; copper, $13.5 \mathrm{mg}$; iodine, $0.19 \mathrm{mg}$; manganese, $37.5 \mathrm{mg}$; selenium, $0.15 \mathrm{mg}$; zinc, $72 \mathrm{mg}$; iron, $72 \mathrm{mg}$; cobalt, $0.19 \mathrm{mg}$; ${ }^{2}$ Values for growing pigs were estimated from the gross composition of the ingredients according to EvaPig (software version 1.3.1.4; INRA, Saint-Gilles, France).

dietary protein. Mineral and vitamin contents were formulated to meet the requirements of animals with strong potential for protein deposition. Dietary phosphorus and calcium requirements were estimated according to Jondreville and Dourmad (2005). The same amount of vitamin and mineral premix was included for both diets.

The nutritional composition of raw materials used in the formulation, except for the values obtained by the chemical analysis (corn and soybean meal), was obtained from the Brazilian Poultry and Swine Tables (Rostagno et al., 2011). Digestible AA values for corn and soybean meal were determined based on the high-performance liquid chromatography analysis (HPLC; obtaining total AA content in each ingredient) and then using the SID coefficients proposed by Sauvant et al. (2004). Feeds were steam-pelleted at $2.5 \mathrm{~mm}$.

The final feed composition of each treatment was obtained by blending the two feeds at each pig visit to the feeder thus creating a complete feed with 
the desired estimated daily SID AA concentration for the diets tested. Four feeding programs (treatments) were evaluated in this study. The control treatment consisted of a daily phase feeding program (DP) in which pigs were fed a blend of feeds $\mathrm{A}$ and $\mathrm{B}$, adjusted each day (at $00 \mathrm{~h} 00$ ) to match $100 \%$ of the daily SID AA diet recommendations (DP100). A negative control treatment in which pigs were fed a blend of feeds $A$ and $B$ to match $70 \%$ of the daily SID AA diet recommendations (DP70). Pigs assigned to SEQ treatments were fed a blend of feeds A and B, adjusted twice a day (at 00h00 and $12 \mathrm{~h} 00$ ), to match two different daily SID AA recommendations during the day. For one SEQ program, the blend was adjusted to match $110 \%$ of the daily SID AA diet recommendations during the first $12 \mathrm{~h}$ of the day $(00 \mathrm{~h} 00$ to $12 \mathrm{~h} 00$, time-period 1 : TP1) and $70 \%$ during the rest of the day $(12 \mathrm{~h} 01-23 \mathrm{~h} 59$, time-period 2: TP2), named SEQ110-70. For the other SEQ program, the blend was adjusted to match $70 \%$ of the daily SID AA diet recommendations during TP1 and $110 \%$ during TP2, named SEQ70-110.

\section{Performance and body composition}

Voluntary feed intake of each animal was recorded by AIPF. Body weight of each animal was measured at the beginning and at the end of each experimental phase (days 0,36, 64 and 85). At days 0, 36, and 64, ultrasound images were collected using ultrasound equipment (coupled with a linear probe of $3.5 \mathrm{~mm}$ ) to evaluate backfat thickness and loin depth. The measurements were taken at the boundary of the thoracic and lumbar vertebrae (P2, behind the last rib), six centimeters from midline (ABCS, 1973). In addition, at days 0, 36, and 64 , the contents of total body fat and body lean mass were measured by dual-energy X-ray absorptiometry (DXA; Hologic Discovery, Hologic Inc., Bedford, MA). For this procedure, pigs were fasted overnight and then anesthetized with acepromazine (tranquilizer), xylazine hydrochloride (sedative), and ketamine hydrochloride (anesthetic) during the scans. Pigs were scanned in the ventral decubitus position. Because the scan room did not have the capacity to receive animals weighing more than $100 \mathrm{~kg}$, the body composition of pigs at day 84 was not measured.

\section{Analytical procedures}

Representative samples of soybean meal and corn were collected before formulation of the diets. Representative samples of feeds A and B were collected once a week throughout the experiment. Soybean meal, corn, and feeds A and B were analyzed for moisture (method 930.15), crude protein (CP; method 992.15), and ash (method 942.05) according to the AOAC (2005) procedures. Calcium and total phosphorus were determined by the ICP-OES method 2011.14 (AOAC, 1990). The AA ingredient composition of the feedstuff (excluding tryptophan) was determined by liquid chromatography in an external laboratory (Campinas, SP,
Brazil) based on the chromatography method described by White et al. (1986). The nutrient content (calculated and analyzed) of the diets are shown in Table 1.

\section{Calculations and statistical analyses}

Total body lean and lipid deposition were calculated as the difference between the respective body constituents estimated at the beginning and the end of experimental phases 1 and 2 .

For the evaluation of feeding behavior, we used AIPF records of each visit to the feeder. Following the method proposed by Andretta et al. (2016a), visits to the feeder by the same pig with intervals lower than $1 \mathrm{~min}$ were considered as a single meal. Feeding information collected on days when the animals were handled (weighed or scanned) were removed from the analysis. After this preliminary procedure for data filtering, we calculated the number of meals per day, feeder occupancy $\left(\min \mathrm{d}^{-1}\right)$, interval between meals (min), feeding time per meal (min), and feed intake per meal (g) of each animal.

Each pig was considered as an experimental unit. Normality was checked for all variables using the Shapiro-Wilks test using the UNIVARIATE procedure. Data was subjected to variance analysis (MIXED procedure) with fixed effects of feeding programs. For the feed intake and feeding behavior analysis, the period (TP1 and TP2) was also considered a fixed effect, and the interaction between feeding program and period was evaluated. The LSMEANS procedure was used to calculate the mean values. Four contrasts were constructed to evaluate the effects of deficient AA diet and SEQ feeding programs $\left(\mathrm{C}_{1}\right.$ : DP100 vs. DP70; $\mathrm{C}_{2}$ : DP100 vs. SEQ110-70; $C_{3}$ : DP100 vs. SEQ70-110; $C_{4}$ : and SEQ110-70 vs. SEQ70-110). Statistical differences were considered significant with $p<0.05$ whereas $0.05<$ $p \leq 0.10$ was considered a tendency. All analyses were performed using the Statistical Analysis System, version 9.3 .

\section{Results}

\section{Animals conditions and experimental feeds}

Throughout the trial, no health issues were detected, and pigs consumed feed and gained weight according to the performance expected for the genotype. Therefore, all animals (15 pigs per feeding program) were kept during the entire experiment.

The chemical analyses of diets showed discrepancy between the formulated and the fed diet A, whose SID Lys values were $12 \%$ lower in the fed diet compared to the formulated diet (Table 1). Due to this difference, the average daily SID Lys diet content for DP100 program was $9 \%$ lower than the NRC recommendation. Although SID Lys diet levels were lower than those recommended by $\mathrm{NRC}$, the target differences between experimental diets $(110,100$ and $70 \%$ SID AA of the recommendations) were reached in the study. 
Considering the total experimental period, the feed A:feed B ratio in the blended feed averaged 63:37, 52:48, 52:48, and 29:71 for DP100, SEQ110-70, SEQ70-110, and DP70 feeding programs, respectively. Because nutrient concentration in feed A was higher than in feed $B$, the corresponding dietary SID Lys concentrations of diets were on average $0.78,0.71$, 0.71, and 0.58 \% for DP100, SEQ110-70, SEQ70-110, and DP70, respectively.

\section{Feeding behavior}

Regardless of the phase, there was no interaction $(p>0.05)$ between feeding program and time period for feeding intake and feeding behavior variables (Table 2), and feeding intake was not affected by the feeding programs $(p>0.05)$. However, during phase 2 , SEQ70-110 pigs showed a tendency toward lower feed intake $(p=0.10)$ compared to SEQ110-70 pigs. During the first phase, feed intake was higher $(p<0.01)$ in TP2 (12h01 to $23 \mathrm{~h} 59$ ) than in TP1 (00h00 to $12 \mathrm{~h} 00$ ), while no effect of time period was observed during the other phases.

During phase 1 , feeding behavior variables were not influenced $(p>0.05)$ by feeding programs. In this phase, feeding time per meal, feeding intake per meal, and the feed consumption rate were higher $(p<0.05)$ in TP2 compared to TP1. Regarding phases 2 and 3, the feed consumption rate was affected by feeding programs $(p<0.05)$. DP100 pigs had a greater $/ p<$ 0.05) feed consumption rate than DP70, SEQ110-70, and SEQ70-110 pigs, while SEQ110-70 pigs had greater $(p<0.05)$ values than SEQ70-110 pigs. During phases 2 and 3 , feed intake per meal and the feed consumption rate were higher in TP2 than in TP1 $(p<0.05)$.

\section{Performance and body composition}

During phase 1 and in the entire experimental period, DP70 pigs had lower $(p<0.05)$ feed efficiency than DP100 pigs (Table 3). In addition, in phase 2, a tendency $(p=0.056)$ toward lower body weight was observed in DP70 pigs compared to DP100 pigs. Regardless of the phase, SEQ110-70 and SEQ70-110 pigs had similar BWG, BW, and feed efficiency compared to DP100 $(p>0.05)$.

Regarding body composition variables (Table 4), feeding programs did not affect backfat thickness and loin muscle depth $(p>0.05)$. During phase 1, pigs in DP70 had lower lean mass gain $(p=0.04)$ and a tendency to lower body lean mass $(p=0.06)$ than pigs in the DP100 program. In this phase, SEQ110-70 pigs showed a tendency toward greater fat gain compared to SEQ70-110 and DP100 pigs $(p=0.08$ and $p=0.10$, respectively). During phase $2, \mathrm{DP} 70$ pigs had a tendency toward lower body lean mass $(p=0.05)$ compared to pigs in the DP100 program. In this phase, SEQ11070 pigs had a greater body fat mass $(p<0.05)$ and a

Table 2 - Feed intake and feeding behavior ${ }^{1}$ of pigs fed according to daily phase (100 and $70 \%$ of the estimated nutritional requirements, DP100 and DP70, respectively) or sequential feeding systems with high-low (SEQ110-70) and low-high (SEQ70-110) amino acid diets.

\begin{tabular}{|c|c|c|c|c|c|c|c|c|c|c|c|c|c|c|}
\hline & \multicolumn{4}{|c|}{ Feeding programs } & \multicolumn{2}{|c|}{ Time-Period $^{2}$} & \multirow{2}{*}{ SEM } & \multicolumn{3}{|c|}{$p$-value ${ }^{3}$} & \multicolumn{4}{|c|}{ Contrast $p$-values ${ }^{4}$} \\
\hline & DP100 & DP70 & SEQ110-70 & SEQ70-110 & TP1 & TP2 & & $\mathrm{F}$ & TP & $\mathrm{F} \times \mathrm{TP}$ & $\mathrm{C}_{1}$ & $\mathrm{C}_{2}$ & $\mathrm{C}_{3}$ & $\mathrm{C}_{4}$ \\
\hline \multicolumn{15}{|l|}{ Phase 1 (0 to 35 days) } \\
\hline Feed intake $\left(\mathrm{kg} \mathrm{d}^{-1}\right)$ & 1.75 & 1.81 & 1.83 & 1.77 & 0.84 & 0.95 & 0.33 & 0.853 & $<0.010$ & 0.556 & 0.368 & 0.280 & 0.748 & 0.444 \\
\hline Number of meals & 12.30 & 11.71 & 11.47 & 11.11 & 6.10 & 5.55 & 0.87 & 0.758 & 0.097 & 0.991 & 0.599 & 0.461 & 0.290 & 0.744 \\
\hline Feeding time per meal (min) & 3.28 & 3.58 & 3.78 & 4.07 & 3.31 & 4.04 & 0.41 & 0.452 & 0.040 & 0.916 & 0.539 & 0.317 & 0.117 & 0.564 \\
\hline Feed intake per meal (g) & 82 & 89 & 90 & 98 & 77 & 102 & 9.36 & 0.575 & $<0.010$ & 0.954 & 0.535 & 0.482 & 0.159 & 0.477 \\
\hline Feeder occupancy (min) & 36.48 & 36.74 & 38.33 & 38.27 & 18.46 & 18.99 & 2.00 & 0.864 & 0.652 & 0.448 & 0.925 & 0.508 & 0.521 & 0.984 \\
\hline Feed consumption rate $(\mathrm{g} \mathrm{min}-1)$ & 25.01 & 24.84 & 24.31 & 24.77 & 23.44 & 26.02 & 0.49 & 0.753 & $<0.010$ & 0.682 & 0.796 & 0.291 & 0.713 & 0.491 \\
\hline \multicolumn{15}{|l|}{ Phase 2 (36 to 63 days) } \\
\hline Feed intake $\left(\mathrm{kg} \mathrm{d}^{-1}\right)$ & 3.10 & 3.08 & 3.12 & 2.92 & 1.50 & 1.55 & 0.06 & 0.681 & 0.447 & 0.112 & 0.828 & 0.601 & 0.261 & 0.103 \\
\hline Number of meals & 9.47 & 10.12 & 9.48 & 9.25 & 4.94 & 4.64 & 0.71 & 0.795 & 0.308 & 0.711 & 0.472 & 0.986 & 0.815 & 0.801 \\
\hline Feeding time per meal (min) & 4.42 & 4.11 & 4.80 & 4.65 & 4.28 & 4.71 & 0.44 & 0.620 & 0.277 & 0.162 & 0.579 & 0.495 & 0.671 & 0.798 \\
\hline Feed intake per meal (g) & 195 & 168 & 199 & 181 & 169 & 203 & 17.27 & 0.447 & 0.023 & 0.166 & 0.205 & 0.847 & 0.498 & 0.385 \\
\hline Feeder occupancy (min) & 37.98 & 37.92 & 41.85 & 39.41 & 19.32 & 19.97 & 2.08 & 0.496 & 0.653 & 0.120 & 0.984 & 0.187 & 0.624 & 0.404 \\
\hline Feed consumption rate $\left(\mathrm{g} \mathrm{min}{ }^{-1}\right)$ & 43.95 & 40.79 & 41.69 & 39.81 & 40.17 & 42.96 & 0.62 & $<0.010$ & $<0.010$ & 0.448 & 0.000 & 0.010 & $<0.001$ & 0.031 \\
\hline \multicolumn{15}{|l|}{ Phase 3 (64 to 84 days) } \\
\hline Feed intake $\left(\mathrm{kg} \mathrm{d}^{-1}\right)$ & 3.10 & 3.16 & 3.10 & 3.05 & 1.58 & 1.53 & 0.08 & 0.977 & 0.504 & 0.116 & 0.476 & 0.539 & 0.728 & 0.777 \\
\hline Number of meals & 7.30 & 8.09 & 7.03 & 7.63 & 3.73 & 3.78 & 0.61 & 0.539 & 0.875 & 0.621 & 0.296 & 0.728 & 0.653 & 0.427 \\
\hline Feeding time per meal (min) & 5.11 & 5.41 & 5.63 & 5.70 & 4.99 & 5.94 & 0.68 & 0.916 & 0.144 & 0.610 & 0.737 & 0.558 & 0.510 & 0.940 \\
\hline Feed intake per meal (g) & 245 & 229 & 263 & 244 & 218 & 272 & 29.80 & 0.872 & 0.060 & 0.636 & 0.691 & 0.650 & 0.983 & 0.635 \\
\hline Feeder occupancy (min) & 32.86 & 36.91 & 36.93 & 37.13 & 17.31 & 18.65 & 2.40 & 0.504 & 0.418 & 0.909 & 0.221 & 0.219 & 0.198 & 0.950 \\
\hline Feed consumption rate $\left(\mathrm{g} \mathrm{min}^{-1}\right)$ & 48.13 & 42.52 & 46.52 & 42.37 & 43.65 & 46.13 & 0.62 & $<0.001$ & $<0.010$ & 0.539 & $<0.001$ & 0.069 & $<0.001$ & $=0.001$ \\
\hline
\end{tabular}


tendency for greater fat mass gain $(p=0.05)$ compared to SEQ70-110 pigs. Between 30 and $93 \mathrm{~kg}$ of BW (global evaluation), SEQ110-70 pigs had a greater fat mass gain $(p<0.05)$ or a tendency for greater fat mass gain $(p=0.10)$ compared to SEQ70-110 and DP100 pigs, respectively.

Table 3 - Performance ${ }^{1}$ of pigs fed according to daily phase (100 and $70 \%$ of the estimated nutritional requirements, DP100 and DP70, respectively) or sequential feeding systems with high-low (SEQ110-70) and low-high (SEQ70-110) amino acid diets.

\begin{tabular}{|c|c|c|c|c|c|c|c|c|c|}
\hline & \multicolumn{4}{|c|}{ Feeding programs } & \multirow{2}{*}{ SEM } & \multicolumn{4}{|c|}{ Contrast $p$-values ${ }^{2}$} \\
\hline & DP100 & DP70 & SEQ110-70 & SEQ70-110 & & $\mathrm{C}_{1}$ & $\mathrm{C}_{2}$ & $\mathrm{C}_{3}$ & $\mathrm{C}_{4}$ \\
\hline \multicolumn{10}{|l|}{ Initial Conditions } \\
\hline BW (kg) & 29.73 & 29.71 & 29.71 & 29.64 & 0.75 & & & & \\
\hline \multicolumn{10}{|c|}{ Phase 1 (0 to 35 days) } \\
\hline$A D G\left(\mathrm{~kg} \mathrm{~d}^{-1}\right)$ & 0.87 & 0.83 & 0.88 & 0.86 & 0.02 & 0.189 & 0.838 & 0.747 & 0.598 \\
\hline G:F & 0.51 & 0.46 & 0.49 & 0.50 & 0.01 & $<0.010$ & 0.165 & 0.643 & 0.350 \\
\hline Final BW (kg) & 60.47 & 58.54 & 60.48 & 60.24 & 0.90 & 0.137 & 0.990 & 0.856 & 0.847 \\
\hline \multicolumn{10}{|c|}{ Phase 2 ( 36 to 63 days) } \\
\hline$A D G\left(\mathrm{~kg} \mathrm{~d}^{-1}\right)$ & 1.16 & 1.09 & 1.19 & 1.16 & 0.03 & 0.119 & 0.562 & 0.953 & 0.529 \\
\hline G:F & 0.37 & 0.36 & 0.39 & 0.38 & 0.01 & 0.388 & 0.204 & 0.694 & 0.376 \\
\hline Final BW (kg) & 92.74 & 88.78 & 93.51 & 91.37 & 1.42 & 0.056 & 0.702 & 0.500 & 0.293 \\
\hline \multicolumn{10}{|c|}{ Phase 3 (64 to 84 days) } \\
\hline$A D G\left(\mathrm{~kg} \mathrm{~d}^{-1}\right)$ & 0.95 & 0.97 & 1.00 & 0.99 & 0.04 & 0.652 & 0.369 & 0.652 & 0.829 \\
\hline G:F & 0.32 & 0.32 & 0.33 & 0.33 & 0.01 & 0.997 & 0.702 & 0.712 & 0.989 \\
\hline Final BW (kg) & 112.67 & 108.87 & 114.55 & 112.20 & 1.81 & 0.146 & 0.467 & 0.856 & 0.365 \\
\hline \multicolumn{10}{|c|}{ Global performance ( 0 to 84 days) } \\
\hline$A D G\left(k g ~ d^{-1}\right)$ & 0.98 & 0.95 & 1.01 & 0.99 & 0.02 & 0.426 & 0.417 & 0.808 & 0.568 \\
\hline $\mathrm{G}: \mathrm{F}$ & 0.40 & 0.37 & 0.40 & 0.40 & 0.01 & 0.001 & 0.660 & 0.980 & 0.678 \\
\hline
\end{tabular}

$\mathrm{SEM}=$ standard error of the mean; $\mathrm{BW}=$ body weight; $A D G=$ average daily gain; $G: F=$ feed efficiency ratio (gain feed intake-1); 1 Each least square mean represents 15 pigs; ${ }^{2}$ Contrasts: $C_{1}$, DP100 vs. DP70; $C_{2}$, DP100 vs. SEQ110-70; $C_{3}$, DP100 vs. SEQ70-110; $C_{4}$, SEQ110-70 vs. SEQ70-110.

Table 4 - Body composition ${ }^{1}$ of pigs fed according to daily phase (100 and $70 \%$ of the estimated nutritional requirements, DP100 and DP70, respectively) or sequential feeding systems with high-low (SEQ110-70) and low-high (SEQ70-110) amino acid diets.

\begin{tabular}{|c|c|c|c|c|c|c|c|c|c|}
\hline & \multicolumn{4}{|c|}{ Feeding programs } & \multirow{2}{*}{ SEM } & \multicolumn{4}{|c|}{ Contrast $p$-values ${ }^{2}$} \\
\hline & DP100 & DP70 & SEQ110-70 & SEQ70-110 & & $\mathrm{C}_{1}$ & $\mathrm{C}_{2}$ & $\mathrm{C}_{3}$ & $\mathrm{C}_{4}$ \\
\hline \multicolumn{10}{|l|}{ Initial Conditions } \\
\hline Backfat thickness (cm) & 0.95 & 0.91 & 0.98 & 0.95 & 0.03 & 0.357 & 0.585 & 0.998 & 0.586 \\
\hline Loin muscle depth (cm) & 3.31 & 3.36 & 3.55 & 3.31 & 0.09 & 0.706 & 0.081 & 0.974 & 0.086 \\
\hline Body lean mass (kg) & 26.05 & 26.04 & 26.27 & 25.81 & 0.56 & 0.991 & 0.775 & 0.754 & 0.553 \\
\hline Body fat mass (kg) & 4.17 & 4.16 & 4.20 & 4.14 & 0.14 & 0.966 & 0.883 & 0.891 & 0.778 \\
\hline \multicolumn{10}{|l|}{ Phase 1 (0 to 35 days) } \\
\hline Final backfat thickness (cm) & 1.29 & 1.31 & 1.38 & 1.37 & 0.05 & 0.725 & 0.176 & 0.199 & 0.943 \\
\hline Final loin muscle depth (cm) & 4.27 & 4.17 & 4.36 & 4.29 & 0.12 & 0.551 & 0.566 & 0.910 & 0.639 \\
\hline Final body lean mass (kg) & 48.77 & 47.04 & 48.50 & 48.38 & 0.66 & 0.063 & 0.755 & 0.665 & 0.893 \\
\hline Final body fat mass (kg) & 10.60 & 10.79 & 11.06 & 10.53 & 0.30 & 0.646 & 0.249 & 0.866 & 0.194 \\
\hline Lean mass gain $\left(\mathrm{kg} \mathrm{d}^{-1}\right)$ & 0.63 & 0.59 & 0.63 & 0.63 & 0.02 & 0.042 & 0.920 & 0.852 & 0.931 \\
\hline Fat mass gain $\left(\mathrm{kg} \mathrm{d}^{-1}\right)$ & 0.18 & 0.19 & 0.20 & 0.18 & 0.01 & 0.674 & 0.103 & 0.883 & 0.081 \\
\hline \multicolumn{10}{|l|}{ Phase 2 (36 to 63 days) } \\
\hline Final backfat thickness $(\mathrm{cm})$ & 1.85 & 1.81 & 2.00 & 1.84 & 0.07 & 0.743 & 0.132 & 0.969 & 0.122 \\
\hline Final loin muscle depth (cm) & 5.83 & 5.71 & 5.98 & 5.84 & 0.12 & 0.479 & 0.406 & 0.977 & 0.422 \\
\hline Final body lean mass (kg) & 73.73 & 70.66 & 73.27 & 72.97 & 1.12 & 0.056 & 0.764 & 0.629 & 0.847 \\
\hline Final body fat mass (kg) & 18.17 & 18.55 & 19.13 & 17.58 & 0.47 & 0.560 & 0.127 & 0.345 & 0.017 \\
\hline Lean mass gain $\left(\mathrm{kg} \mathrm{d}^{-1}\right)$ & 0.90 & 0.84 & 0.89 & 0.89 & 0.03 & 0.132 & 0.764 & 0.901 & 0.871 \\
\hline Fat mass gain $\left(\mathrm{kg} \mathrm{d}^{-1}\right)$ & 0.27 & 0.28 & 0.29 & 0.25 & 0.01 & 0.850 & 0.367 & 0.266 & 0.050 \\
\hline \multicolumn{10}{|c|}{ Global body composition (0 to 63 days) } \\
\hline Lean mass gain $\left(\mathrm{kg} \mathrm{d}^{-1}\right)$ & 0.76 & 0.74 & 0.77 & 0.75 & 0.02 & 0.529 & 0.669 & 0.799 & 0.502 \\
\hline Fat mass gain $\left(\mathrm{kg} \mathrm{d}^{-1}\right)$ & 0.22 & 0.23 & 0.24 & 0.22 & 0.01 & 0.819 & 0.102 & 0.453 & 0.021 \\
\hline
\end{tabular}

$\mathrm{SEM}=$ standard error of the mean; ${ }^{~}$ Each least square mean represents 15 pigs; ${ }^{2}$ Contrasts: $\mathrm{C}_{1}$, DP100 vs. DP70; $\mathrm{C}_{2}$, DP100 vs. SEQ110-70; $\mathrm{C}_{3}$, DP100 vs. SEQ70$110 ; \mathrm{C}_{4}, \mathrm{SEQ110-70} \mathrm{vs.} \mathrm{SEQ70-110.}$ 


\section{Discussion}

\section{General overview}

Optimizing dietary protein supply depends on how AA supply in the feed is balanced according to nutrient requirements of animals. Given that optimal concentration of nutrients in the diet progressively decreases over the growth period, one way to improve protein utilization is to concomitantly adjust dietary concentration of AA (daily phases feeding; Pomar et al., 2014). However, this feeding program does not take into account variations in feeding behavior and endocrine and metabolic status that occur during the 24-hour-day cycle. For instance, pigs show a biphasic diurnal feeding pattern characterized by a small peak in feed consumption at the beginning of the day and a larger peak at the end of the day (Boumans et al., 2015; Andretta et al., 2016b). This feeding behavior occurs in connection with the diurnal fluctuation in blood hormones (insulin, glucagon, growth hormone, etc.) and by variations in the sensitivity of several metabolic pathways to hormonal regulation (Koopmans et al., 2006). Therefore, the balance in protein metabolism also fluctuates over the day influenced mainly by insulin circadian rhythms (Koopmans et al., 2005; Koopmans et al., 2006). In this sense, there is nonnegligible variation in insulin-stimulated AA and glucose utilization during the day cycle that is characterized by greater efficiency of protein metabolism in the morning compared to the evening (Koopmans et al., 2006). This may represent a paradigm shift because the optimal dietary AA level may no longer be considered static during the day, but rather a dynamic process. In order to move toward precision nutrition, it may be more accurate to consider the daily variations in endocrine and metabolic status of pigs and then adjusting the feeding programs accordingly. In this regard, studies evaluating sequential feeding are of utmost importance. For instance, according to the results obtained in this study, similar lean meat gain between DP100 and SEQ may suggest no protein metabolic advantage of varying AA diet composition throughout the day in growing-finishing pigs fed ad libitum. Furthermore, the greater fat gain obtained by providing pigs a higher-low AA diet level may suggest a shift in the energy balance during the day.

\section{Feeding behavior}

Growing-finishing pigs usually have greater feed consumption in the evening than in the morning (de Haer and de Vries, 1993; Andretta et al., 2016b). In our study, this feeding pattern was observed in pigs in the different feeding programs where a greater feed intake (12\% in phase 1 ) and feed intake per meal (on average $18 \%$ for all the phases) were observed in TP2 (12h01 to 23h59) compared to TP1 (00h00 to 12h00). These results are consistent with the literature /Chen et al., 2010) that also reported a higher feed intake per visit to the feeder in the evening. Our results showed lower feed consumption rates in DP70 pigs compared to DP100, in agreement with Montgomery et al. (1978), who found a reduction in feed consumption rate in pigs receiving AA-deficient diet. This might be explained by a lower concentration of some AA (e.g., valine; Val and tryptophan; Trp) that have an important role in the synthesis and/or secretion of hormonal regulators of feed intake (Ettle and Roth; 2004, Gloaguen et al., 2011). The lower feed consumption rate in SEQ70-110 and the slight decrease in daily feed intake compared to SEQ110-70 feeding program may be related to the fact that pigs are more susceptible to Val and Trp deficiencies in the morning than in the evening.

\section{Performance and body composition}

The sequential feeding programs used in this study were designed based on previous studies that reported better protein use in the morning than in the evening (Koopmans et al., 2005; Koopmans et al., 2006). In this regard, we hypothesized that offering more or less AA in the morning and evening (i.e., SEQ110-70 and SEQ70-110) may provide a better adjustment of AA supply to pigs during the day. This can imply an improvement of AA balance, decreased nutrient excess and, consequently, improves resource-use efficiency with a favorable positive effect on growth performance. According to our results, this hypothesis is not accepted because no improvement of average daily gain (ADG) and lean gain was observed for pigs fed with sequential feeding programs. Indeed, even consuming less AA in TP1 or in TP2, SEQ pigs had similar growth performance and lean gain to DP100 pigs. Furthermore, similar ADG and lean gain observed between SEQ11070 and SEQ 70-110 programs showed that feeding pigs with diets that differed in AA levels during the day did not result in better resource-use efficiency in protein metabolism. Thus, according to our results, there is no protein metabolic advantage to providing more or less $\mathrm{AA}$ in the morning and in the evening (i.e., SEQ110-70 and SEQ70-110).

The results of our study disagree with Xie et al. (2015) who evaluated two sequential systems (high CP diet in the morning and low $\mathrm{CP}$ in the evening and vice versa) and found greater A DG in the high-low CP group than in the control group (normal CP diet level during an entire day). However, in the study above, the authors reported that AA requirements were met regardless of the treatments, which did not occur in our study where SEQ pigs received lower AA levels. Furthermore, in the study by Xie et al. (2015), pigs received a diet with $22 \%$ of CP (high CP diet), which is not viable in commercial conditions, due to the high cost of the diet and environmental impact. These different responses could be associated to the different feeding programs used (ad libitum or restricted). In these studies, which evaluated AA metabolism (Koopmans et al., 2005; Koopmans et al., 2006) and response of pigs fed different nutrient concentrations 
(Xie et al., 2015) during the day, animals were fed with one meal in the morning and another in the evening. These meal frequency induced differences to protein metabolism, where a lower plasma concentration of urea and $\alpha$-amino nitrogen was observed for pigs fed two meals per day compared to pigs fed ad libitum (Le Naou et al., 2014). Thus, possibly only less frequent meals may increase AA utilization for protein synthesis in the morning, while an ad libitum program may not have an effect.

Regarding body composition, our results showed body fat mass and gain of $8 \%$ higher in SEQ110-70 pigs than in SEQ70-110 pigs. Furthermore, fat mass gain for SEQ110-70 pigs was not significant; however, it tended to increase by $8 \%(p=0.10)$ compared to DP100 pigs. The lower protein/carbohydrate ratio for SEQ110-70 and the greater consumption and feed intake per meal in TP2 suggested that pigs from this treatment had more energy available from carbohydrates for fat deposition in TP2. This result disagrees with an earlier experiment showing greater fat loss $(17 \%)$ of pigs fed a protein diet (95\% of daily protein and $0 \%$ of starch) in the morning (at $08 \mathrm{~h} 00$ ) and a starch diet (5\% daily protein and $100 \%$ starch) in the evening (at 16h00, van den Borne et al., 2007). Previous research has concentrated on human nutrition (with fewer meals per day) and much less attention has been paid to the effect of varying nutrition composition during the day in a pig production context where an ad libitum regime is normally applied. Thus, further studies evaluating the metabolic responses when varying AA diets throughout the day for pigs fed ad libitum are of utmost importance. For instance, we suggest that in an ad libitum regime fat deposition may increase for pigs receiving a diet containing more carbohydrates in the evening.

The slight reduction in feed intake $(p=0.10)$ observed for SEQ70-110 compared to SEQ110-70 may also suggest that less energy was available for fat deposition in this treatment. Thus, if the pork market benefits from leaner meat, the sequential feeding system with low-AA diet in the morning and high-AA diet in the evening may be a more promising feeding program to reduce fat deposition. However, according to our study, compared to DP100 and DP70, no differences in fat deposition $(p=0.232$ and $p=0.143$, respectively, data not shown) were observed for pigs (60 to $93 \mathrm{~kg}$ of BW) fed a higher AA diet in TP2 (SEQ70-110). As mature pigs have greater propensity to deposit adipose tissue, other studies could be conducted with heavier pigs (e.g., 100 to $130 \mathrm{~kg} \mathrm{BW}$ ) and using higher AA diet levels in TP2 than those evaluated in our study.

In conclusion, with regard to daily phase feeding, a sequential feeding regime varying AA diet level over the day (high-low or low-high) in a 12-hour-cycle interval does not improve weight gain, feed efficiency, or lean gain for growing-finishing pigs. Moreover, feeding pigs a diet with higher AA levels during the first $12 \mathrm{~h}$ of the day and lower AA levels during the rest of the day increases fat deposition. Finally, further studies are needed to assess the effects of AA levels for sequential feeding programs different from those evaluated in this study on the performance, body composition, and metabolic response of growing-finishing pigs.

\section{Acknowledgements}

The authors thank the São Paulo Research Foundation (FAPESP, grant 2018/15559-7, Brazil), Coordination for the Improvement of Higher Level Personnel (CAPES, Brazil), Brazilian National Council for Scientific and Technological Development (CNPq, Brazil) and Agroceres Pic (Brazil) for the financial support for this study.

\section{Authors' Contributions}

Data acquisition: Silva, W.C.; Santos, L.S.; Veira, A.M.; Fraga, A.Z. Data analysis: Silva, W.C.; Santos, L.S.; Design of methodology: Campos, P.H.R.F.; Hauschild, L. Writing and editing: Silva, W. C.; Campos, P.H.R.F.; Hauschild, L.

\section{References}

Andretta, I.; Pomar, C.; Rivest, J.; Pomar, J.; Radünz, J. 2016a. Precision feeding can significantly reduce lysine intake and nitrogen excretion without compromising the performance of growing pigs. Animal 10: 1137-1147.

Andretta, I.; Pomar, C.; Kipper, M.; Hauschild, L.; Rivest, J. 2016b. Feeding behavior of growing-finishing pigs reared under precision feeding strategies. Journal of Animal Science 94: 3042-3050.

Andretta, I.; Pomar, C.; Rivest, J.; Pomar, J.; Lovatto, P.A.; Radünz Neto, J. 2014. The impact of feeding growing-finishing pigs with daily tailored diets using precision feeding techniques on animal performance, nutrient utilization, and body and carcass composition. Journal of Animal Science 92: 3925-3936.

Associação Brasileira dos Criadores de Suínos [ABCS]. 1973. Brazilian Carcass Classification Method $=$ Método Brasileiro de Classificação de Carcaças. 2ed. ABCS, Estrela, RS, Brazil (in Portuguese).

Association of Official Analytical Chemists - International [AOAC]. 1990. Official Methods of Analysis. 15ed. AOAC, Arlington, VA, USA.

Association of Official Analytical Chemists - International [AOAC]. 2005. Official Methods of Analysis. 18ed. AOAC, Gaithesburg, MD, USA.

Boumans, I.J.M.M.; Bokkers, E.A.M.; Hofstede, G.J.; de Boer, I.J.M. 2015. Understanding feeding patterns in growing pigs by modelling growth and motivation. Applied Animal Behaviour Science 171: 69-80.

Bouvarel, I.; Barrier-Guillot, B.; Larroude, P.; Boutten, B.; Leterrier, C.; Merlet, F.; Vilarino, M.; Roffidal, L.; Tesseraud, S.; Castaing, J. 2004. Sequential feeding programs for broiler chickens: twenty-four-and forty-eight-hour cycles. Poultry Science 83: 49-60. 
Chen, C.Y.; Misztal, I.; Tsuruta, S.; Herring, W.O.; Holl, J.; Culbertson, M. 2010. Influence of heritable social status on daily gain and feeding pattern in pigs. Journal of Animal Breeding and Genetics 127: 107-112.

de Haer, L.C.M.; de Vries, A.G. 1993. Effects of genotype and sex on the feed intake pattern of group housed growing pigs. Livestock Production Science 36: 223-232.

Ettle, T.; Roth, F.X. 2004. Specific dietary selection for tryptophan by the piglet1. Journal of Animal Science 82: 1115-1121.

Gloaguen, M.; Le Floc'h, N.; Brossard, L.; Barea, R.; Primot, Y.; Corrent, E.; van Milgen, J. 2011. Response of piglets to the valine content in diet in combination with the supply of other branched-chain amino acids. Animal 5: 1734-1742.

Jondreville, C.; Dourmad, J.-Y. 2005. Phosphorus in pig nutrition $=$ Le phosphore dans la nutrition des porcs. INRA Production Animal 18: 183-192 (in French).

Koopmans, S.J.; van der Meulen, J.; Dekker, R.; Corbijn, H.; Mroz, Z. 2006. Diurnal variation in insulin-stimulated systemic glucose and amino acid utilization in pigs fed with identical meals at 12-h intervals. Hormone and Metabolic Research 38: 607-613.

Koopmans, S.J.; van der Meulen, J.; Dekker, R.; Corbijn, H.; Mroz, Z.; Group, A.S. 2005. Diurnal rhythms in plasma cortisol, insulin, glucose, lactate and urea in pigs fed identical meals at 12-hourly intervals. Physiology \& Behavior 84: 497-503.

Le Naou, T.; Floc'h, N.; Louveau, I.; van Milgen, J.; Gondret, F. 2014. Meal frequency changes the basal and time-course profiles of plasma nutrient concentrations and affects feed efficiency in young growing pigs. Journal of Animal Science 92: 2008-2016.

Letourneau Montminy, M.P.; Boucher, C.; Pomar, C.; Dubeau, F.; Dussault, J-P. 2005. Impact de la méthode de formulation et du nombre de phases d'alimentation sur le coût d'alimentation et les rejets d'azote et de phosphore chez le porc charcutier. Journées Recherche Porcine 37: 25-32 (in French, with abstract in English).
Montgomery, G.W.; Flux, D.S.; Carr, J.R. 1978. Feeding patterns in pigs: the effects of amino acid deficiency. Physiology \& Behavior 20: 693-698.

National Research Council [NRC]. 2012. Nutrient Requirements of Swine. 11ed. NRC, Washington, DC, USA.

Pomar, C.; Pomar, J.; Dubeau, F.; Joannopoulos, E.; Dussault, J-P. 2014. The impact of daily multiphase feeding on animal performance, body composition, nitrogen and phosphorus excretions, and feed costs in growing-finishing pigs. Animal 8: 704-713.

Rostagno, H.S.; Albino, L.F.T.; Donzele, J.L.; Gomes, P.C.; Oliveira, R.F.; Lopes, D.C.; Ferreira, A.S.; Barreto, S.L.T. 2011. Brazilian Tables for Poultry and Pigs: Feedstuffs Composition and Nutritional Requirements $=$ Tabelas Brasileiras para Aves e Suínos: Composição de Alimentos e Exigências Nutricionais. Editora UFV, Viçosa, MG, Brazil (in Portuguese).

Sauvant, D.; Perez, J-M.; Tran, G. 2004. Tables of composition and nutritional value of feed materials: pigs, poultry, cattle, sheep, goats, rabbits, horses and fish. Wageningen Academic Press, Versailles, France.

van den Borne, J.J.G.C.; Schrama, J.W.; Heetkamp, M.J.W.; Verstegen, M.W.A.; Gerrits, W.J.J. 2007. Synchronising the availability of amino acids and glucose increases protein retention in pigs. Animal 1: 666-674.

White, J.; Hart, R.; Fry, F. 1986. An evaluation of the Waters PicoTag system for the amino acid acid analysis of food materials. Journal of Automatic Chemistry 8: 170-177.

Xie, C.; Wu, X.; Li, J.; Fan, Z.; Long, C.; Liu, H.; Even, P.C.; Blachier, F.; Yin, Y. 2015. Effects of the sequence of isocaloric meals with different protein contents on plasma biochemical indexes in pigs. PLoS ONE 10: e0125640. 